\section{Physics in an Amusement Park: The Experience of University Students}

\author{
Michelle Tiamzon Natividad \\ Physics Department, De La Salle University, \\ 2401 Taft Avenue, Manila, Philippines 1004 \\ Tel: 632-524-4611 E-mail: michelle.natividad@dlsu.edu.ph \\ Voltaire Mallari Mistades (Corresponding author) \\ Physics Department, De La Salle University, \\ 2401 Taft Avenue, Manila, Philippines 1004 \\ Tel: 632-524-4611Ｅ-mail: voltaire.mistades@dlsu.edu.ph
}

Accepted: December 9, 2011 Published: January 09, 2012

Doi:10.5296/ijld.v2i1.1253ＵRL: http://dx.doi.org/10.5296/ijld.v2i1.1253

\begin{abstract}
The paper describes an amusement park activity that provided a unique opportunity to facilitate tertiary-level student's understanding of Physics. During the out-of-class session, the students were engaged in activities where they verified the validity of physics concepts learned inside the classroom. By experiencing physical phenomenon in a fun manner they developed a new experimental basis for determining whether an answer calculated in a classroom makes sense. An amusement park experience is an authentic real-life experiential learning tool that enhances students' understanding of the conceptual and contextual applications of the laws of Physics.
\end{abstract}

Keywords: Amusement Park Physics, Constructivism, Experiential Learning, Physics Education Research, Scaffolding, University Students 


\section{Introduction}

Recent developments in Physics Education Research have seen the teaching of physics evolve from an approach that is based around conceptual content to one in which the concepts are taught using a contextual approach. The advantage of contextual teaching is that students can link physics to their lives in the real world. Whitelegg and Parry (1999) note that when physics is taught using a contextual approach, students apply previous knowledge to real life situations, thus motivating the students to learn more.

Several educational theories serve as the foundation for the amusement park activity, among them are: constructivist learning philosophy, experiential learning, and Vygotsky's notion of scaffolding. Each theory will be presented to allow the reader to appreciate the raison d' etre of the activity.

\subsection{Constructivist Learning Philosophy}

Constructivist philosophy puts forward the idea that learners construct knowledge for themselves - each learner individually (and socially) constructs meaning - as he or she learns. Constructivism shifts the focus of learning from rote memorization to learning by building conceptual structures through reflection and abstraction in order to apply knowledge across domains. Hensen (2001) reiterates that building conceptual structures requires the learner to see connections by using structures of knowledge that are generalizable and transferable. Teachers who espouse constructivism see learning as an active process where the learner constructs new ideas based on past and present experiences. The learner creates mental models to manipulate, propose hypotheses, discover new principles, or explain new concepts.

\subsection{Experiential Learning}

Experiential Learning, also known as hands-on or inquiry-based learning, has long been a staple of science education. It is an approach that goes beyond traditional book-learning and memorization. It acknowledges the social aspect of learning and is designed to equip students with real-world skills. Experiential Learning is the process of making meaning from direct experience (Kolb, 1984). An example of experiential learning is going to the zoo and learning through observation and interaction with the zoo environment, as opposed to reading about animals from a book. Thus, one makes discoveries and experiments with knowledge firsthand, instead of hearing or reading about others' experiences.

Kolb (1984) states that in order to gain genuine knowledge from an experience, certain abilities are required:

1. the learner must be willing to be actively involved in the experience;

2. the learner must be able to reflect on the experience;

3. the learner must possess and use analytical skills to conceptualize the experience; and

4. the learner must possess decision-making and problem-solving skills in order to use the new ideas gained from the experience. 


\subsection{Vygotsky's Notion of Scaffolding}

For the tasks prescribed in this learning activity, the goal is to allow the students to do as much as they can on their own, and then to provide assistance when it is needed so that the task can be successfully completed. A metaphor that has been used to describe this kind of teaching is "scaffolding". The student is seen as constructing an edifice that represents his/her cognitive abilities. The construction starts from the ground going up, building on the foundation of what is already known and can be done, with new knowledge being added on top of the existing ones.

\section{Discussion}

The educational theories described above were integrated into the teaching pedagogy through the use of a learning activity in the amusement park where students are required to answer questions that will enable them to demonstrate their understanding of physics concepts (Kinematics, Newton's Laws of Motion, Conservation of Energy, Momentum \& Collisions, Electricity, and Magnetism).

The guide questions that the students worked on include:

- While riding the Dodgem or Bump n' Splash, ask your friends to bump your car / boat at an angle from either side. Determine the direction of the force you feel. Make several diagrams that would show the forces. [Momentum \& Collisions]

- Ride the Wheel of Fate, when the ride is continuously moving, when do you feel the greatest acceleration: at the top, at the bottom, at the side going up, or at the side going down, or is the motion constant? Give a possible explanation for your observation. [Newton's Laws of Motion]

- Watch the Condor in motion. Measure the speed of the inner and the outer rotation (in rev/min). Then, while riding the Condor, determine whether you feel the larger rotation, the smaller rotation, or both. What could be the reason for this observation? [Circular Motion]

Safety should always come first in any student activity, thus, throughout the activity, the students were reminded to ensure their own safety. In the guide questions, for example, one instruction goes like, "Ride the Log Jam twice; first sit perpendicular to the seat. Next time, lean back. Describe the difference in sensation between both instances. WARNING: Park management advises against leaning forward anytime during this ride."

Based on the students' answers to the questions and their reflection papers, we can say that the activity provided an authentic real-life experiential learning tool in enhancing students' understanding of conceptual and contextual applications of the laws of Physics.

The students were able to articulate their line of reasoning by using their experience together with the scientific explanation, 
"When the Wheel of Fate (Ferris Wheel) ride is continuously moving, we felt the greatest acceleration at the bottom. Based on scientific experiments, this is so because the forces acting on the carriage (the rotational force and the person's weight) combine at the bottom that would result in greater acceleration compared to when the carriage is at the top. When the carriage is at the top of the Ferris Wheel, the person's weight pushes toward the center of rotation thus cancelling the normal force exerted by the seat pushing outward. So basically, when you are at the top, the forces cancel out each other, but when you are at the bottom, they add up together, so the greatest acceleration is at the bottom, and we felt this 'heavy' feeling near the bottom of the Ferris Wheel."

"The first application of Physics principles in the Dodgem (bump car ride) is that the cars run on electricity through the poles that they are connected to the grid in the ceiling. The electrical energy is converted into kinetic energy, thus making the cars move. Another application in this ride is that of Newton's third law of motion, which is the Action-Reaction Law. Every time a car gets hit, it generates a force equal in magnitude but opposite in direction to the force that it came in contact with. That makes me feel a force every time I try to hit the car that my friend is riding."

The students were very honest with their responses. For instance, when instructed to ride the Space Shuttle (roller coaster ride) twice at different positions and to give a comparison of how they felt from the various positions, the student's response was,

"It was really difficult to compare how we felt in the different positions we rode because we were already a little bit dizzy from the previous time we rode on the Space Shuttle before changing positions."

The amusement park activity also provided opportunities for Cooperative Learning. For instance, in answering the question for the Rio Grande Rapids ride, students need to work with the members of their group, "Ride the Rio Grande Rapids at least twice with several friends. Take note of your position in the gondola as it leaves the embarking area. Take note also of your position relative to the heaviest person in your group. Is there a specific position (in front of, at the back of, or across the heaviest person) that consistently gets wet? Give a possible explanation for the principle that governs the motion of the boat." Working together as a team was something that the students appreciated in the activity as seen in what the students wrote in their reflection papers,

“... the trip was an absolute happiness. My friends and I had super fun with the rides and we had the chance to bond together outside of school."

The experience made the students view going to an amusement park from a different perspective, as shared by a student in his paper,

"When I go to a theme park in the past, all I did was to have fun. During this trip, I observed the rides more intently to see what causes them to be so thrilling and I got to appreciate the physics more as it was being applied to something like this." 
The activity made the students realize that "physics is everywhere, even in places like an amusement park - you just have to think about it". The awareness of the students of the things around them had been heightened by the experience,

"I'll definitely be more aware of the physics behind the things that I observe in my everyday experiences."

"The trip taught me to be more observant of things. Before this trip, I took things forgranted such as riding a car, television, gadgets. I just accepted them for what they are and what they can do for me. I was not that curious on how it worked or how it was made. But as an Engineering student, I was challenged by the activity, that hopefully by the time I graduate, I get a deeper understanding of how something functions."

\section{Conclusion}

Scientific concepts are easier to understand when a connection to everyday life is established. The learning activity, "Physics in an Amusement Park", provided tertiary-level students with the opportunity to experience and act out scientific theories while having fun. The activities helped the students understand how things work and how the underlying physical principles are manifested in their environment. The concepts that were learned inside the classroom acceleration, force, velocity, speed, gravitational effects, inertia, momentum, conservation of energy, electricity and magnetism - were strengthened by the activity. The physical concepts were understood, measured, and internalized by the students while they were having fun, whirling about on the merry-go-round, riding a bump car, swinging up and down a pirate ship, plunging down a roller coaster hill, and even getting all wet in a river rapids ride!

\section{Acknowledgement}

The authors thank the De La Salle University Physics Department for the support extended to this research undertaking.

\section{References}

Hensen, K.T. (2001). Curriculum planning: Integrating multiculturalism, constructivism, and educational reform. (Second edition). Boston: McGraw-Hill Higher Education.

Kolb, D.A. (1984). Experiential Learning: experience as the source of learning and development. New Jersey: Prentice-Hall.

Whitelegg, E. and Parry, M. (1999). Real-life contexts for learning physics: meanings, issues and practice. Physics Education, 34(2), 68-72. 